\title{
Early detection of COPD in general practice: implementation, workload and socioeconomic status. A mixed methods observational study
}

\section{* Joseph AM Dirven', Huibert J Tange1, Jean WM Muris', Karin MA van Haaren², Gerrit Vink ${ }^{3}$, Onno CP van Schayck ${ }^{1}$}

\author{
Caphri School of Public Health and Primary Care, Department of General Practice, Maastricht University Medical Centre, Maastricht, \\ The Netherlands \\ 2 Dutch College of General Practitioners, Utrecht, The Netherlands \\ ${ }^{3}$ Dutch Lung Foundation, Amersfoort, The Netherlands
}

Received 20th March 2013; revised 24th May 2013; accepted 4th June 2013; online 21st August 2013

\begin{abstract}
Background: Chronic obstructive pulmonary disease (COPD) is underdiagnosed in general practice. Our aim was to implement a population-based approach for the early detection of COPD and to assess its impact on primary care workload and costs, and the influence of socioeconomic status (SES).

Methods: An observational study with mixed methods was performed in 10 Dutch general practices of either low or moderate to high SES. The Respiratory Health Screening Questionnaire was posted during a three-month period to all persons aged 45, 55, and 65 years (one age group per month). The practices calculated the risk, and patients at high risk of COPD were invited for spirometry at the practice. The general practitioner used the spirometric results and a consultation to establish a clinical diagnosis. Qualitative and quantitative data on workload, cost, and barriers were evaluated.

Results: Ten practices returned 293 (35.3\%) COPD risk tests for the three age groups. Participants from low SES practices responded better than those from moderate to high SES practices (40.8\% vs. 30.5\%). In practices with low SES $17.9 \%$ of the tests indicated high risk compared with $16.1 \%$ in practices with moderate to high SES. Nine patients (23\%) were newly diagnosed with COPD. The healthcare providers' extra workload averaged 18.5 hours during the three months for one standard practice. The average cost of this survey programme (three age groups in three months) was $€ 520$ for low SES practices and $€ 398$ for moderate to high SES practices. All healthcare providers affirmed that the extra workload in this survey model is acceptable and feasible when finances are compensated.

Conclusions: Early detection of COPD is feasible in daily life primary care. In moderate to high SES practices the costs of detecting COPD were less than in low SES practices.

(C) 2013 Primary Care Respiratory Society UK. All rights reserved.

JAM Dirven et al. Prim Care Respir J 2013; 22(3): 338-343

http://dx.doi.org/10.4104/pcrj.2013.00071
\end{abstract}

Keywords COPD, early detection, socioeconomic status, workload, general practice

\section{Introduction}

Chronic obstructive pulmonary disease (COPD) is a progressive disease which usually begins many years before it is diagnosed. Many patients with COPD remain undiagnosed and are potentially unknown to healthcare providers.' Previous epidemiological studies in Europe have shown that COPD affects $9 \%$ of the adult population, of whom most are smokers. ${ }^{2,3}$ The prevalence of COPD in Dutch general practices is $2 \%$. In many western countries a further $2 \%$ of COPD cases remain undiagnosed. ${ }^{4}$

The reasons for underdiagnosis of COPD have mainly been reported as underuse of spirometry by doctors and the lack of awareness by patients of signs, symptoms, and risk factors. This is especially important in the early stages of the disease as early COPD may already impair daily activities and reduce the quality of life. ${ }^{5}$

\footnotetext{
* Corresponding author: Mr Joseph AM Dirven, CAPHRI School of Public Health and Primary Care, Department of General Practice, Maastricht University Medical Centre, Peter Debyeplein 1, 6226HA Maastricht, The Netherlands. Tel: +31 433882314 E-mail: jos.dirven@maastrichtuniversity.nl
} 
Early detection is relevant and may lead to people being able to perceive their symptoms. Besides symptoms, people with undetected COPD have many lifestyle problems including smoking and lack of daily physical activity. Smoking is the most preventable cause of premature death, ${ }^{6}$ and smoking cessation is a very costeffective measure. ${ }^{7}$ In COPD it can have a positive effect on the impact and progression of the disease. ${ }^{8}$ The health benefits and long-term effects of reduced tobacco consumption are well documented. ${ }^{9,10}$

Many people with smoking-related illnesses visit general practices every year. ${ }^{11}$ As many as $80 \%$ of smokers visit their general practitioner (GP) once or more annually. ${ }^{12}$ Thus, general practices offer a good opportunity for smoking cessation interventions. ${ }^{13}$

Low socioeconomic status (SES) is an important risk factor for COPD, and it is not well known how low SES groups cope with their lifestyle. In people with low SES there is a higher prevalence of COPD, ${ }^{14}$ whether or not they smoke. ${ }^{15}$ Low SES correlates significantly with lower lung function, even after adjustment for smoking status, occupational exposures, and race or ethnic origin. ${ }^{16}$

People with low SES participate less in online mass interventions, and those with a low educational level use the internet less frequently, as do addicted young smokers. ${ }^{17}$ If low SES groups are recruited, they refrain from follow-up actions more often than moderate to high SES groups. ${ }^{18}$ We know that there are many smokers among undiagnosed COPD patients, especially in low SES groups. When the target group consists mainly of smokers with low SES, the most suitable and effective gateway for recruiting respondents is probably through general practice. ${ }^{19}$

The process of early detection of COPD in general practice is complex and requires a structured method of identifying patients with risk factors and symptoms of COPD in a stepwise manner.

Mounting evidence suggests that early detection, adequate diagnosis, and maintenance treatment of COPD - along with smoking cessation and an increase in daily physical activity - may help to provide symptom control, lessen disease progression, and lead to better long-term outcomes for COPD. ${ }^{20}$ There have been several initiatives to develop COPD case-finding programmes in specific risk groups and in different clinical settings. ${ }^{21-25}$ Stepwise early detection programmes with a population-based approach seem to be feasible in an experimental research setting..$^{26-28}$

An evidence base for an early detection programme of COPD as such is not enough to introduce this programme successfully into clinical practice. In general, there is a gap between the introduction of a guideline and its effective use. Lugtenberg et al. found that, besides lack of evidence, organisational constraints, lack of knowledge by the user, and lack of clarity of the guideline itself are also important barriers for using the guideline. ${ }^{29}$ It is therefore important to study and solve potential barriers for implementation before introducing a new nationwide guideline.

The aim of the present study was to evaluate the feasibility of implementing an early detection programme for COPD. Research questions were:

1. Are there barriers related to organisational factors such as workload and financial constraints?
2. Are there barriers related to user characteristics such as attitude or knowledge?

3. Are there barriers related to patient characteristics such as the dominant SES signature of the practice?

\section{Methods}

\section{Setting and design}

An early detection programme for COPD was implemented in 10 general practices in two cities in the south of the Netherlands in May, June and July 2012. The practices were stratified into two classes (low SES and moderate to high SES) based on postal codes according to the Dutch Health Authority public register. ${ }^{30}$

The implementation of the programme was studied in an observational study with a mixed methods design including both quantitative and qualitative methods.

\section{Population}

Candidates for the early detection programme were all people aged 40-70 years, excluding those already diagnosed with asthma or COPD or with other serious lung diseases such as lung cancer, pneumoconiosis, tuberculosis, bronchiectasis, and pneumonectomy. People using oxygen supplementation and those with impaired mobility were also excluded.

Five low SES practices and five moderate to high SES practices were randomly chosen from the public list of the Dutch Health Authority ${ }^{30}$ and recruited. Prerequisites for participation were: (a) no involvement in another COPD early detection or case finding procedure in the last five years; (b) obligatory participation in the study of the GP, practice assistant (PA), and practice nurse (PN); and (c) available and recent electronic medical records (EMRs).

\section{Intervention}

The script of the early detection programme has been described in the COPD Prevention Consultation (CPC) model by the Dutch College of General Practitioners ${ }^{31}$ and consists of four stages (Figure 1).

The first stage is to send out the Respiratory Health Screening Questionnaire (RHSQ), a validated questionnaire for screening patients at risk of COPD. ${ }^{32,33}$ It contains 10 simple questions about age, smoking history, body weight, height, and respiratory complaints (Table 1). The risk of COPD is determined by adding the points of individual items of the RHSQ score card: low risk $(<16.5$ points), medium risk (16.5-19.5 points), or high risk (>19.5 points). There are two versions of the RHSQ. One version is meant for public use and includes the score card for self-calculation and was applied by the Dutch Lung Foundation in a mass media campaign (www.longfonds.nl/ontdek-copd-op-tijd). The other version is meant for use by family practices and does not include the score card. The PA sends the RHQS to eligible people and calculates the risk scores after return of the RHQS. The latter was used in this implementation study.

The second stage is capturing and analysing the RHSQ data in a Digital Risk Test (DRT) tool. People with a high-risk score are invited for spirometry. Other people only receive a letter with general lifestyle advice and a reference to the public website of the Dutch College of General Practitioners (www.thuisarts.nl).

The third stage is a consultation with the PN. During this 
Figure 1. Script of the early detection programme. RHSQ=Respiratory Health Screening Questionnaire

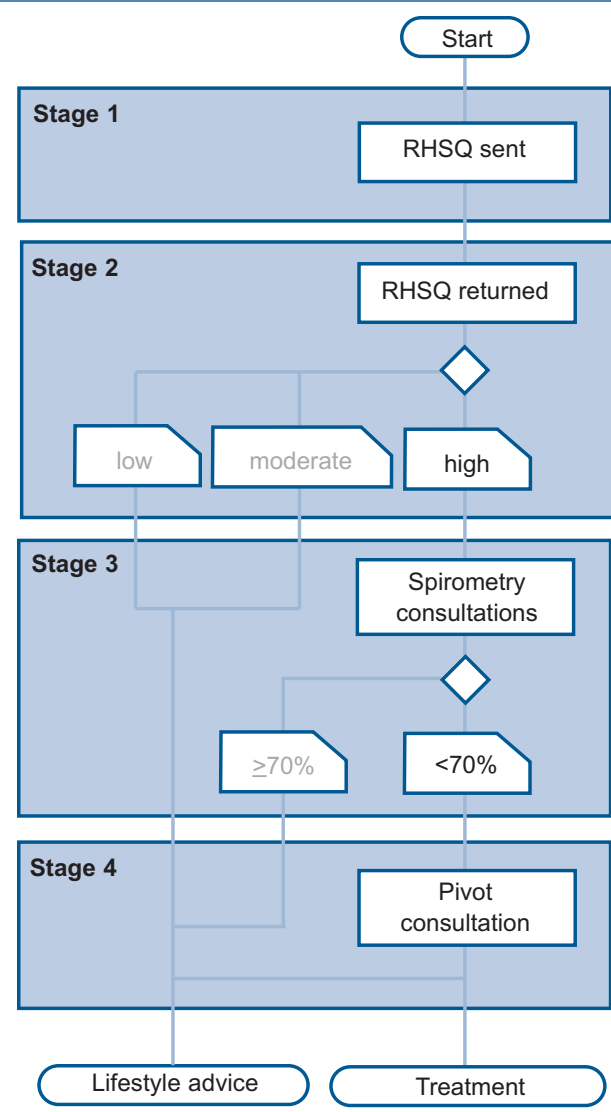

consultation the Medical Research Council (MRC) dyspnoea scale and the Clinical COPD Questionnaire (CCQ) are filled out and postbronchodilator spirometry is performed. People with an abnormal spirometry test are then invited in for a doctor consultation.

The fourth stage is a consultation with the family practitioner. During this consultation the COPD diagnosis and GOLD stage is confirmed. A COPD diagnosis is based on the combination of a postbronchodilator $\mathrm{FEV}_{1} / \mathrm{FVC}$ ratio $<0.7$ and the physician's clinical evaluation (www.nhg.org). The follow-up procedure is explained and, when indicated, smoking cessation advice is given and/or medication is started. All data are recorded in the DRT tool.

\section{Implementation strategy}

A short care providers' meeting was arranged in each practice to explain the aims and methods of the study and to confirm the prerequisites for participation. The indicated implementation strategy was to let practices include one age group each month, thus spreading the workload. For this three-month implementation study, all eligible people aged 45 were invited in the first month, those aged 55 in the second month, and those aged 65 in the third month. Respondents could complete the RHSQ on paper or electronically on a website.

\section{Measurement instruments}

Patient data such as RHSQ results, spirometry results, GOLD stage and advice given were retrieved from the DRT tool.
Table 1. Respiratory Health Screening Questionnaire (RHSQ) score card

\begin{tabular}{|c|c|c|c|}
\hline \multicolumn{2}{|c|}{ Question } & \multirow{2}{*}{$\frac{\text { Answer }}{40-49}$} & \multirow{2}{*}{$\frac{\text { Score }}{0}$} \\
\hline 1. & What is your age? & & \\
\hline & Age group, years & $50-59$ & 4 \\
\hline & & $60-69$ & 8 \\
\hline 2(a) & $\begin{array}{l}\text { How many cigarettes have you } \\
\text { smoked per day? }\end{array}$ & ....... cigarettes & \\
\hline \multirow[t]{2}{*}{ 2(b) } & Are you smoking now? & Yes 0 & \\
\hline & & No $\mathrm{O}$ & \\
\hline $3(a)$ & How many years have you smoked? & ....... years & \\
\hline \multirow[t]{4}{*}{$3(b)$} & Pack years I have smoked & $0-14$ & 0 \\
\hline & & $15-24$ & 2 \\
\hline & & $25-49$ & 3 \\
\hline & & $50+$ & 7 \\
\hline 4. & What is your weight? & ........ kg & \\
\hline \multirow[t]{4}{*}{5.} & What is your height? & ........m $\mathrm{m}$ & \\
\hline & Body mass index, $\mathrm{kg} / \mathrm{m}^{2}$ & $>29.7$ & 0 \\
\hline & & $25.4-29.7$ & 1 \\
\hline & & $<25.4$ & 5 \\
\hline \multirow[t]{3}{*}{6.} & Does the weather affect your cough? & Yes & 3 \\
\hline & & No & 0 \\
\hline & & Do not cough & 0 \\
\hline \multirow[t]{2}{*}{7.} & Do you have phlegm without a cold? & Yes & 3 \\
\hline & & No & 0 \\
\hline \multirow[t]{2}{*}{8.} & Do you have phlegm in the morning? & Yes & 0 \\
\hline & & No & 3 \\
\hline \multirow[t]{2}{*}{9.} & Do you wheeze (frequency)? & Never & 0 \\
\hline & & $\begin{array}{l}\text { Sometimes } \\
\text { or often }\end{array}$ & 4 \\
\hline \multirow[t]{2}{*}{10.} & Have or had any allergies? & Yes & 0 \\
\hline & & No & 3 \\
\hline
\end{tabular}

The following practice/healthcare provider data were acquired:

- Workload was measured with a questionnaire (SCIT-z) administered to the GP, PN, and PA.

- Potential barriers for adoption and implementation of health innovations in primary care were inventoried by a validated questionnaire for healthcare providers. ${ }^{34}$ This questionnaire includes a total of 27 questions about 24 aspects of the characteristics of the innovation, the healthcare provider, the patient, and contextual factors such as regulations and financial aspects (Table 2). All questions were scored on a 5-point Likert scale.

\section{Outcome measures}

1. Outcome measures for organisational feasibility were workload (in hours per staff member per practice) and cost per practice. Cost was calculated by the number of RHSQ tests and spirometry consultations needed to find one positive diagnosis, divided by their unit cost.

2. Outcome measures for user-bound feasibility were perceived barriers based on the scores of practice personnel on different dimensions of a validated questionnaire for assessing barriers and facilitators of health innovations. 
Table 2. Barriers and facilitators' assessment instrument

\begin{tabular}{rll} 
& Domain & Aspect \\
\hline Innovation characteristics & \\
1 & Innovation & Compatibility \\
2 & Innovation & Time investment \\
3 & Innovation & Specificity/sensitivity \\
4 & Innovation & Didactic benefit \\
5 & Innovation & Attractiveness \\
\hline Care provider characteristics & \\
6 & Care provider & Attitude/role perception \\
7 & Care provider & Knowledge motivation \\
8 & Care provider & Doubts innovation \\
9 & Care provider & Life/working style \\
10 & Care provider & Education \\
11 & Care provider & Involvement \\
\hline
\end{tabular}

\section{Patient characteristics}

12 Patient

13 Patient

14 Patient

15 Patient

16 Patient

17 Patient

Age

Ethnicity

Financial situation/SES

Number of patient contacts

Health status

Motivation to change

Context characteristics

18 Context

Group norms/socialisation

19 Context

Reimbursement/insurance system

20 Context

Law/regulations

21 Context

22 Context

23 Context

Opening hours of practice

24 Context

Facilities

Practice building

Grey boxes indicate significant barriers identified by the responding

healthcare providers.

SES=socioeconomic status.

3. Outcome measures for patient-bound feasibility were the differences in response to and the effectiveness of the early detection programme between low SES and moderate-to-high SES practices.

These quantitative outcome measures were extended with qualitative information from the semi-structured interviews of healthcare professionals.

\section{Analysis of data}

Most analyses were descriptive. Differences in participation rates were tested with $\chi^{2}$ or Fisher's exact tests.

\section{Results}

\section{Response, effectiveness, and SES}

A total of 831 RHSQ tests were distributed, of which 293 (35\%) were completed and returned (Table 3): 156 (41\%) from the 382 low SES practices and 137 (31\%) from the 449 moderate-to-high SES practices $(p<0.05)$. The website was used by 29 of the 156 respondents (19\%) in low SES practices and by 56 of the 137 respondents $(41 \%)$ in moderate-to-high SES practices $(p<0.01)$.

Overall, 50 respondents (17\%) had a high-risk score, 28 (18\%) in low SES practices and $22(16 \%)$ in moderate-to-high SES practices (NS). The response among high-risk respondents to an invitation for spirometry was $21(75 \%)$ in low SES practices and $18(82 \%)$ in moderate-to-high practices (NS). Nine (23\%) new COPD diagnoses were established, seven (33\%) in low SES practices and two (11\%) in moderate-to-high SES practices (NS).

\section{Workload}

The workload for the early detection programme was shared between the PA, PN, and GP. On average, a PA spent 9.5 hrs on the programme, a PN spent 6 hrs, and a GP spent 3 hrs during the three months of the study (Table 4). Thus, in total, a standard practice team (1 GP + 1 PN + 1 PA) spent 18.5 hrs in three months on the programme, varying from 14.5 hrs for moderate-to-high SES practices to 26 hrs for low SES practices. As a result, the direct cost for practice personnel varied from $€ 398$ for moderate-to-high SES practices to $€ 520$ for low SES practices, with an average of $€ 460$ per practice.

\section{Perceived barriers and facilitators and health provider satisfaction}

The barriers for successful implementation perceived by the majority of teams were the ethnicity and SES of patients and the absence of financial compensation and limited supporting staff of the practice. No barriers were perceived in the nature of the programme itself or in the qualifications of the care providers (Table 2).

The DRT tool was a welcome support for the early detection programme. The 45 mins reserved for spirometry consultation was

Table 3. Response rates and yield of the early detection programme

\begin{tabular}{llll} 
Results & All practices & Low SES & Moderate-to-high SES \\
\hline Patients registered in practices & 23,100 & 11,000 & 12,100 \\
\hline Patients aged 45, 55, 65 years & 956 & 425 & 513 \\
\hline Patients with exclusion criteria & 107 & 43 & 64 \\
\hline Number of RHSQs distributed & 831 & 382 & 449 \\
\hline Responders on RHSQ* & $293(35 \%)$ & $156(41 \%)$ & $137(31 \%)$ \\
\hline Responders on website* & 85 & 29 & 56 \\
\hline High-risk score on RHSQ & $50(17 \%)$ & $28(18 \%)$ & $22(16 \%)$ \\
\hline Underwent spirometry (high-risk) & $39(78 \%)$ & $21(75 \%)$ & $18(82 \%)$ \\
\hline New COPD cases detected & $9(23 \%)$ & $7(33 \%)$ & $2(11 \%)$ \\
\hline COPD cases detected per standard general practice $(\mathrm{N}=2,350)$ & 0.9 & 1.5 & 0.4 \\
\hline * $<0.05,\left(\chi^{2}\right.$ test). COPD=chronic obstructive pulmonary disease, RHSQ=Respiratory Health Screening Questionnaire, SES=socioeconomic status.
\end{tabular}




\begin{tabular}{|c|c|c|c|}
\hline Activity & Care provider & Hours & Total \\
\hline Practice Assistant (PA) & & & 9.5 \\
\hline \multicolumn{4}{|l|}{ Stage l: Questionnaire mailing } \\
\hline a. Performing computer extraction & PA & 1 & \\
\hline $\begin{array}{l}\text { b. Compiling a mailing list using } \\
\text { exclusion criteria }\end{array}$ & PA & 1 & \\
\hline $\begin{array}{l}\text { c. Mailing procedure (addressing, } \\
\text { folding, posting) }\end{array}$ & PA & 3.5 & \\
\hline \multicolumn{4}{|c|}{$\begin{array}{l}\text { Stage II: Assessing questionnaire respondents } \\
\text { using the Digital Risk Test (DRT) tool }\end{array}$} \\
\hline a. Processing the scores into the DRT & PA & 2 & \\
\hline $\begin{array}{l}\text { b. Processing website respondents } \\
\text { scores }\end{array}$ & PA & 1 & \\
\hline $\begin{array}{l}\text { c. Posting lifestyle letter to medium } \\
\text { and low risk } \\
\text { Posting invitation letter to high risk } \\
\text { for spirometry }\end{array}$ & PA & 1 & \\
\hline
\end{tabular}

Practice Nurse (PN)

6

Stage III: Performing spirometry

a. One spirometry takes 45 mins PN 6 (totally 8 spirometries performed)

b. Including processing MRC and CCQ score

c. Including making appointment with GP

General Practitioner (GP)

Stage IV: Physician consultation

a. Interpreting clinical finding

GP 1 including spirometry

b. Coaching patient and coordinating GP follow-up

(first month $1 \mathrm{hr}$; second month 0.5hr; third month: 0.5hr)

Total PA and NP and GP hours

considered short because of patient questions and administration. Healthcare providers would have preferred more time for spirometry consultation (60 mins). Healthcare providers considered that the extra workload spent on the programme was feasible for a short time but, in case the activities became structural, they felt they would need extra personnel together with financial compensation.

\section{Discussion}

\section{Main findings}

This study showed that early detection of COPD is feasible in daily general practice in terms of participation, workload, costs, and provider satisfaction. Practices found the workload to be feasible, but only had to invite one age group per month. The yield of new cases of COPD was worthwhile; in all practices the yield was $23 \%$ of highrisk spirometries and 33\% in low SES groups, which is in line with the RCT published also in this issue of the PCRJ..$^{35}$
The average response to the questionnaire mailing was 35\%. Other population-based detection surveys ${ }^{35}$ have achieved a similar rate of $35 \%$, and $33 \%$ in the Cardiovascular Prevention Consultation Survey in 2010. In the high-risk group, 78\% were willing to undergo spirometry; this high percentage may be due to the direct invitation by the practice. Internet usage was 19\% in low SES groups and $41 \%$ in moderate to high SES groups. This trend is also found in studies using internet interventions for smoking cessation.

After evaluation the healthcare providers in the general practices assessed the script book for implementation as a comprehensive working tool (Table 2). They were motivated and had enough knowledge and education for participation. They recommended previous case finding of all respiratory diagnoses in the Eletronic Medical Dossier (EMD) before starting the early detection programme.

\section{Interpretation of findings in relation to previously published work}

To our knowledge there is no previously published implementation study measuring workload in a COPD screening programme.

\section{Strengths and limitations of this study}

The strength of this study is that it took place in a routine healthcare situation; all procedures took place in the daily practice setting where all medical activities continued as usual. The health workers were free to schedule the extra workload in their agenda. All PNs were qualified nurses and adequately trained spirometrists. Another strength of this study is the attention paid to the SES of the participants. A limitation is that we decided not to study the feasibility of early detection in the whole age cohort of 40-70 years. Implications for future research, policy and practice Based on this study, we recommend early detection of COPD, especially in practices with a low SES signature. We advise spreading the extra workload over a longer period of two years and to invite only one age cohort per month. Diagnoses of COPD and asthma should be well documented in the Electronic Medical Record (EMR).

\section{Conclusions}

In this real-life COPD early detection programme the yield of new COPD diagnoses was substantial - considering the limited number of patients screened - and the associated workload seemed to be acceptable. Extra financial means are necessary to compensate for the extra hours of work.

\section{Handling editor Anthony D'Urzo Statistical review Gopal Netuveli}

Acknowledgements We thank Mr Hubert Maljaars and Mrs Mascha Twellaar for their work as research assistants. Ethical approval was obtained from the Medical Ethics Review Board (MERB), Atrium Hospital, Heerlen (MERB number 12N36, Dutch Trial Register NTR3391).

Conflicts of interest The authors declare that they have no conflicts of interest in relation to this article. OCPvS is an Assistant editor of the PCRJ, but was not involved in the editorial review of, nor the decision to publish, this article.

Contributorship Mr Vink of the Lung Foundation chaired the project quality group chairman. The Dutch College of General Practitioners provided input by Dr van Haaren as a member of the quality group. Dr Tange was responsible for the statistical analyses. Dr Muris advised as general practitioner. Professor van Schayck was finally responsible for the study and manuscript. Dr Dirven was principle researcher and project coordinator. All authors contributed to the manuscript and 
approved the final version.

Funding Funding was provided by The Dutch Lung Foundation. Financial compensation of $€ 1000$ has been offered to the participating general practices.

\section{References}

1. Global Initiative for Chronic Obstructive Lung Disease (GOLD). Global strategy for diagnosis, management, and prevention of COPD. Available from: www.goldcopd.com.

2. Lundback B, Nystrom L, Rosenhall L, Stjernberg N. Obstructive lung disease in northern Sweden: respiratory symptoms assessed in a postal survey. Eur Respir $J$ 1991:4:257-66

3. Sobradillo Pena V, Miravitlles M, Gabriel R, et al. Geographic variations in prevalence and underdiagnosis of COPD: results of the IBERPOC multicentre epidemiological study. Chest 2000;118:981-9. http://dx.doi.org/10.1378/chest.118.4.981

4. Soriano JB, Zielinski J, Price D. Screening for and early detection of chronic obstructive pulmonary disease. Lancet 2009;374:721-32.

http://dx.doi.org/10.1016/S0140-6736(09)61290-3

5. Miravitlles M, Soriano JB, Garcia-Rio F, et al. Prevalence of COPD in Spain: impact of undiagnosed COPD on quality of life and daily life activities. Thorax 2009;64:863-8. http://dx.doi.org/10.1136/thx.2009.115725

6. World Health Organization. WHO Report on the Global Tobacco Epidemic: the MPOWER package. Geneva: World Health Organization, 2008.

7. Anthonisen NR, Connett JE, Kiley JP, et al. Effects of smoking intervention and the use of an inhaled anticholinergic bronchodilator on the rate of decline of FEV1. The Lung Health Study. JAMA 1994;272:1497-505.

http://dx.doi.org/10.1001/jama.1994.03520190043033

8. Pisinger C, Godtfredsen NS. Is there a health benefit of reduced tobacco consumption? A systematic review. Nicotine Tob Res 2007;9:631-46. http://dx.doi.org/10.1080/14622200701365327

9. Godtfredsen NS, Lam TH, Hansel TT, et al. COPD-related morbidity and mortality after smoking cessation: status of the evidence. Eur Respir J 2008;32:844-53. http://dx.doi.org/10.1183/09031936.00160007

10. Bize R, Burnand B, Mueller Y, Rege WM, Cornuz J. Biomedical risk assessment as an aid for smoking cessation. Cochrane Database Syst Rev 2009;2. http://dx.doi.org/110.1002/14651858.CD004705.pub3

11. van den Berg M, de Bakker D, Kolthof E, Cardol M, van den Brink-Muinen A. De werkdruk van de huisarts: zorgvraag en arbeidsduur in 1987 en in 2001. [The general practitioner's workload: demand for care and working hours in 1987 and 2001.] Medisch Contact 2003;58:1054-6.

12. Richmond R, Kehoe L, Webster I, Wodak A, Heather N. General practitioners' promotion of healthy lifestyles: what patients think. Aust NZ J Public Health 1996;20:195-200. http://dx.doi.org/10.1111/j.1753-6405.1996.tb01818.x

13. Stead LF, Bergson G, Lancaster T. Physician advice for smoking cessation. Cochrane Database Syst Rev 2008. http://dx.doi.org/10.1002/14651858.CD000165.pub3

14. Kanervisto M, Vasankari T, Laitinen T, Heliovaara M, Jousilahti P, Saarelainen S. Low socioeconomic status is associated with chronic obstructive airway diseases. Respir Med 2011;105:1140-6. http://dx.doi.org/10.1016/j.rmed.2011.03.008

15. Yin $P$, Zhang $M$, Li $Y$, Jiang $Y$, Zhao $W$. Prevalence of COPD and its association with socioeconomic status in China: findings from China Chronic Disease Risk Factor Surveillance 2007. BMC Public Health 2011;11:586. http://dx.doi.org/10.1186/1471-2458-11-586

16. Hegewald MJ, Crapo RO. Socioeconomic status and lung function. Chest 2007;132:1608-14. http://dx.doi.org/10.1378/chest.07-1405

17. Etter JF, Perneger TV. A comparison of cigarette smokers recruited through the
Internet or by mail. Int J Epidemiol 2001;30:521-5. http://dx.doi.org/10.1093/ije/30.3.521

18. Dalstra JA, Kunst AE, Geurts JJ, Frenken FJ, Mackenbach JP. Trends in socioeconomic health inequalities in the Netherlands, 1981-1999. J Epidemiol Community Health 2002;56:927-34. http://dx.doi.org/10.1136/jech.56.12.927

19. Marmot M. Social determinants of health inequalities. Lancet 2005;365:1099-104.

20. Price D, Freeman D, Cleland J, Kaplan A, Cerasoli F. Earlier diagnosis and earlier treatment of COPD in primary care. Prim Care Respir J 2011;20:15-22. http://dx.doi.org/10.4104/pcri.2010.00060

21. Buffels J, Degryse J, Liistro G. Diagnostic certainly, co-morbidity and medication in a primary care population with presumed airway obstruction: the DIDASCO2 study. Prim Care Respir J 2009;18:34-40. http://dx.doi.org/10.3132/pcrj.2008.00047

22. Vandevoorde J, Verbanck S, Gijssels L, et al. Early detection of COPD: a case finding study in general practice. Respir Med 2007;101:525-30. http://dx.doi.org/10.1016/j.rmed.2006.06.027

23. Geijer RMM. Detection of COPD in smokers. Thesis. Julius Center for Health Sciences and Primary Care, University Medical Center, Utrecht, The Netherlands, 2006.

24. Stratelis $G$, Jacobsson $P$, Molstad $S$, Zetterstrom O. Early detection of COPD in primary care: screening by invitation of smokers aged 40 to 55 years. Br $J$ Gen Pract 2004; 54:201-06.

25. Piperno D, Bart F, Serrier P, Zureik M, Finkielsztejn L. [General practice patients at risk of chronic obstructive pulmonary disease.] Presse Med 2005;34:1617-22. http://dx.doi.org/10.1016/S0755-4982(05)84236-8

26. van Schayck CP, Halbert RJ, Nordyke RJ, Isonaka S, Maroni J, Nonikov D. Comparison of existing symptom-based questionnaires for identifying COPD in the general practice setting. Respirology 2005;10:323-33. http://dx.doi.org/10.1111/j.1440-1843.2005.00720.x

27. Calverley PM, Nordyke RJ, Halbert RJ, Isonaka S, Nonikov D. Development of a population-based screening questionnaire for COPD. COPD 2005;2:225-32. http://dx.doi.org/10.1081/COPD-57594

28. Dirven JAM, Muris JWM, van Schayck CP. COPD screening in general practice using a telephone questionnaire. J COPD 2010;5:352-9. http://dx.doi.org/10.3109/15412555.2010.510547

29. Lugtenberg M, Zegers-van Schaick JM, Westert GP, Burgers JS. Why don't physicians adhere to guideline recommendations in practice? An analysis of barriers among Dutch general practitioners. Implement Sci 2009;4:54. http://dx.doi.org/10.1186/1748-5908-4-54

30. Nederlandse Zorgautoriteit. Available from: wuw.nza.nl.

31. Pilot COPD Prevention Consultation. Dutch College of General Practitioners, Utrecht, 2012.

32. Price DB, Tinkelman DG, Halbert RJ, et al. Symptom-based questionnaire for identifying COPD in smokers. Respiration 2006;73:285-95. http://dx.doi.org/10.1159/000090142

33. van Schayck CP, Loozen JM, Wagena $E$, et al. Detecting patients at a high risk of developing chronic obstructive pulmonary disease in general practice: cross sectional case finding study. BMJ 2002;324:1370. http://dx.doi.org/10.1136/bmj.324.7350.1370

34. Peters MAJ, Harmsen M, Laurant MGH, Wensing M. Room for improvement? Barriers to and facilitators for improvement of patient care. Nijmegen: Centre for Quality of Care Research (WOK), Radboud University Nijmegen Medical Centre, 2002.

35. Dirven JAM, Tange HJ, Muris JWM, van Haaren KMA, Vink G, van Schayck CP. Early detection of COPD in general practice: patient or practice managed? A randomised controlled trial of two strategies in different socioeconomic environments. Prim Care Respir J 2013;22(3):331-7. http://dx.doi.org/10.4104/pcrj.2013.00070

\section{Available online at http://www.thepcrj.org}

